\title{
O uso do ácido hialurônico na harmonização facial
}

\author{
The use of hyaluronic acid in facial matching \\ El uso de ácido hialurónico en el emparejamiento facial
}

\author{
Thaise Primo Santos Saboia \\ ORCID: https://orcid.org/0000-0002-7600-4265 \\ Instituto Educacional Santa Catarina, Brasil \\ E-mail: drathaisesaboia@gmail.com \\ Mara Régina Lucena Cabral \\ ORCID: https://orcid.org/0000-0003-2739-7231 \\ Instituto Educacional Santa Catarina, Brasil \\ E-mail: mararegina.uft@gmail.com \\ Liberta Lamarta Favoritto Garcia Neres \\ ORCID: https://orcid.org/0000-0003-1327-605X \\ Instituto Educacional Santa Catarina, Brasil \\ E-mail: liberta.neres@iescfag.edu.br
}

\begin{abstract}
Resumo
O preenchimento facial com ácido hialurônico é um procedimento minimamente invasivo que vem se destacando positivamente ao longo dos anos na área da Biomedicina estética. Devido à grande demanda por opções não cirúrgicas, surgiram na harmonização facial, técnicas referentes ao uso de preenchedores dérmicos, que são capazes de proporcionar aumento de volume, equilíbrio simétrico e restauração dos contornos faciais, promovendo o rejuvenescimento. Objetivo: Realizar uma revisão bibliográfica sobre o uso do ácido hialurônico como preenchedor na harmonização facial dentro das extensões estéticas, bem como analisar as intercorrências acometidas pelo ácido hialurônico. Método: Tratou-se de um estudo exploratório e descritiva. A construção da revisão foi feita através de um levantamento utilizando artigos científicos e periódicos, selecionadas a partir das fontes: Google Acadêmico, PubMed e Scielo. Resultados: Foram analisados os artigos mais relevantes, a fim de se obter uma melhor execução do trabalho, desenvolvendo informações quanto à literatura a respeito deste tema. Conclusão: É notável que o uso do ácido hialurônico injetável vem crescendo a cada dia, e tem um papel fundamental nos tratamentos para prevenção e gerenciamento do envelhecimento, e através disso vem conquistando lugar de destaque, melhorando assim o bem estar físico, mental e social do paciente.
\end{abstract}

Palavras-chave: Harmonização; Ácido hialurônico; Envelhecimento; Hialuronidase.

\begin{abstract}
Facial filling with hyaluronic acid is a minimally invasive procedure that has stood out positively over the years in the field of Aesthetic Biomedicine. Due to the great demand for non-surgical options, techniques related to the use of dermal fillers emerged in facial harmonization, which are capable of providing volume increase, symmetrical balance and restoration of facial contours, promoting rejuvenation. Objective: To carry out a literature review on the use of hyaluronic acid as a filler in facial harmonization within aesthetic extensions, as well as to analyze the complications affected by hyaluronic acid. Method: This was an exploratory and descriptive study. The construction of the review was made through a survey using scientific articles and periodicals, selected from the sources: Academic Google, PubMed and Scielo. Results: The most relevant articles were analyzed in order to obtain a better execution of the work, developing information about the literature on this topic. Conclusion: It is remarkable that the use of injectable hyaluronic acid is growing every day, and has a fundamental role in treatments for the prevention and management of aging, and through this it has been gaining a prominent place, thus improving physical, mental and social well-being of the patient.
\end{abstract}

Keywords: Harmonizing; Hyaluronic acid; Aging; Hyaluronidase.

\section{Resumen}

El relleno facial con ácido hialurónico es un procedimiento mínimamente invasivo que se ha destacado positivamente a lo largo de los años en el campo de la Biomedicina Estética. Debido a la gran demanda de opciones no quirúrgicas, han surgido técnicas relacionadas con el uso de rellenos dérmicos en la armonización facial, que son capaces de proporcionar aumento de volumen, equilibrio simétrico y restauración de los contornos faciales, favoreciendo el rejuvenecimiento. Objetivo: Revisar la literatura sobre el uso del ácido hialurónico como relleno en la armonización facial en extensiones estéticas, así como analizar las complicaciones afectadas por el ácido hialurónico. Método: estudio exploratorio y descriptivo. La construcción de la revisión se realizó a través de una encuesta con artículos científicos y 
revistas, seleccionados de las fuentes: Google Scholar, PubMed y Scielo. Resultados: Se analizaron los artículos más relevantes con el fin de obtener una mejor ejecución del trabajo, desarrollando información sobre la literatura sobre el tema. Conclusión: Cabe destacar que el uso de ácido hialurónico inyectable ha ido creciendo día a día, jugando un papel fundamental en los tratamientos para la prevención y manejo del envejecimiento, y con ello ha ido ganando protagonismo, mejorando la salud física, mental y social. bienestar del paciente.

Palabras clave: Armonizador; Ácido hialurónico; Envejecimiento; Hialuronidasa.

\section{Introdução}

Nos últimos tempos a sociedade está cada vez mais atenta não só no que se refere ao cuidado com o corpo como também com o facial, todavia, o envelhecimento é um processo multifatorial, inevitável e acontece de forma natural. Com o aumento da expectativa de vida eleva-se também o crescimento de buscas para melhorar os aspectos faciais, isso ocorre porque com o avanço da idade é possível observar o envelhecimento da pele, principalmente na face; tornando-se desta forma um dos motivos que levam as pessoas a buscarem recursos estéticos para diminuírem os efeitos do tempo (Ferreira \& Capobianco, 2016).

Com o processo de envelhecimento a derme e epiderme tendem a reduzir quantitativa e qualitativamente por meio da redução progressiva da atividade mitocondrial e da degradação e diminuição do colágeno da matriz celular. O colágeno é uma peça fundamental do tecido conjuntivo, torna-se gradativamente mais rígido e há uma perda considerável das moléculas de água, contendo o desenvolvimento dos nutrientes com posterior redução da habilidade de regeneração dos tecidos. Com isso, o envelhecimento associado à perda gradual dos coxins de gordura da face e ao enfraquecimento da elasticidade da pele e coadjuva para a base de sulcos e depressões, comprometendo o equilíbrio facial (Sudaram \& Fagien, 2015).

De acordo com Salvi e Maia (2018), a partir de procuras não cirúrgicas em que as pessoas pudessem fazer os procedimentos e tratamentos tendo uma rotina normal, surgiu-se um novo conceito de beleza que é a harmonização facial, que nada mais é do que o conjunto de técnicas e protocolos utilizados, capazes de amenizar o efeito do tempo, ajustando volume, restaurando equilíbrio dos contornos faciais.

Os tratamentos minimamente invasivos e tecnologias existentes no mercado, têm sido bastante utilizados para atender essa finalidade. Uma das escolhas de maior destaque nesse processo de gerenciamento do envelhecimento consiste na aplicação do Ácido Hialurônico (AH), um preenchedor dérmico, onipresente e biocompatível cujas as características físicas e químicas estariam relacionadas à correção de sulcos, rugas e assimetrias, promovendo harmonização dos contornos faciais (Salvi \& Maia, 2018).

Desde 2011, o Conselho Federal de Biomedicina (CFBM) regulamentou na resolução 200/2011, que a Biomedicina Estética como uma especialidade, visto que, biomédicos estetas são profissionais aptos para exercer com competência procedimentos estéticos corporais, bem como procedimentos dentro da harmonização facial (CFBM, 2011).

Atualmente a Harmonização Facial vem sendo desempenhada cada vez mais pelos Biomédicos Estetas, praticada através de técnicas novas, com o objetivo de harmonizar a face de forma natural, buscando sempre resultados suaves, respeitando o biotipo, idade, a anatomia da face de cada paciente, atendendo assim os resultados esperados, amenizando o processo de envelhecimento causado pelo tempo.

Apesar do Ácido Hialurônico ser destaque dentre os preenchedores temporários com mais aplicabilidade dentro da Harmonização facial (HF), é necessária uma avaliação sobre as suas indicações para cada indivíduo e seus efeitos biológicos.

A disposição do presente estudo foi de produzir uma revisão bibliográfica avaliando as vantagens da utilização do AH na harmonização facial, bem como amenizar o processo de envelhecimento e atenuar as disfunções estéticas. 


\section{Materiais e Métodos}

O presente trabalho refere-se a uma revisão bibliográfica narrativa, norteando a busca de estudos pesquisados em fontes credíveis de informação científica utilizando-se as bases de dados eletrônicas PubMed/MEDLINE (US National Library of Medicine), Scielo, Lilacs e Saúde baseada em evidências. Todos os trabalhos encontrados online e na integra. Foram pesquisados artigos em língua portuguesa e inglesa publicados no período de 2010 a 2021. Os descritores utilizados na busca foram: harmonização facial, preenchimento facial; ácido hialurônico; envelhecimento.Além disso, foram feitos levantamentos de documentos oficiais, legislações e normativas que regulamentam e norteiam a profissão do Biomédico Esteta.

Foram consideradas como critério de inclusão: pesquisas científicas, relatos de casos com abordagem do assunto relacionado ao uso do ácido hialurônico na harmonização facial, e revisões sobre envelhecimento facial, indexados nas plataformas científicas supracitadas.

\section{Revisão de Literatura}

O envelhecimento é um processo incessante que afeta diretamente a harmonia facial, diminuindo as funções naturais da nossa pele, tornando os fatores intrínsecos e extrínsecos excessivos, influenciados pela alteração do material genético, exposição solar, tabagismo, etilismo, alimentação e estresse (Haddad, et al., 2017). Essa variação de pele relacionada ao envelhecimento, demonstra-se através das rugas, manchas de pele, perda de elasticidade e volume, reposicionamento da gordura facial e reabsorção óssea (Conceição, et al., 2021).

Os coxins de gordura da face atuam proporcionando volume no tecido mole, possibilitando um suporte voluntario como um travesseiro para a pele e para outras estruturas mais profundas do rosto. Em uma face jovem, essa camada de gordura entrega um tônus de pele mais firme e sustentador. A atrofia desse tecido no processo de envelhecimento, entra como principal precursor, mostrando os sinais aparentes de envelhecimento. Além disso, as condições de nutrição da derme são reduzidas através da mudança da qualidade e fornecimento de sangue e líquidos nas camadas adjacentes (Correia \& Santos, 2019).

Figura 1. A imagem mostra o processo de envelhecimento e a redução dos coxins gordurosos.
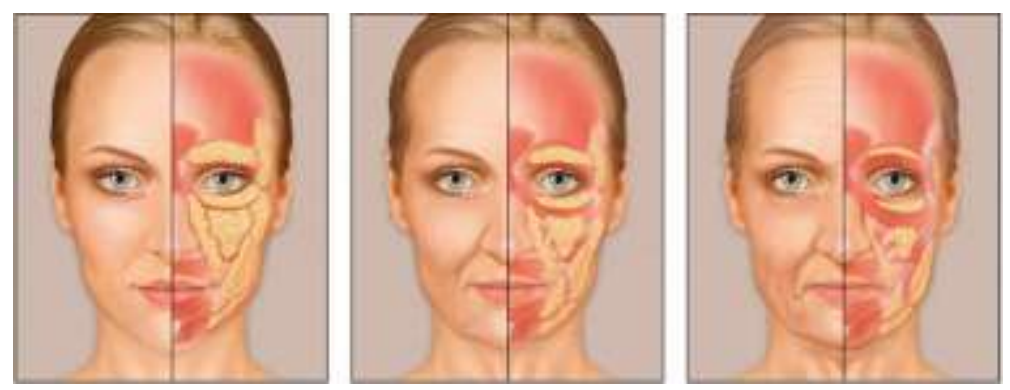

Fonte: Coimbra, et al. (2013).

De acordo com Oliveira, et al., (2014), o desgaste da pele com o decorrer do tempo, está relacionado a redução do número de células no organismo, e ao funcionamento desorganizado das que se mantem. Com isso a derme fica com menor espessura, as fibras de elastina se degradam, e há uma redução da vascularização, dessa forma o ácido hialurônico, um dos componentes importantes para a hidratação da pele, volume, sustentação e jovialidade também sofre as consequências do envelhecimento (Munhoz, et al., 2020).

O ácido hialurônico é um polímero natural, altamente hidrofílico que pode ter origem natural, é encontrado na matriz extracelular da pele, tecido conectivo e no humor vítreo, ou na forma sintética, pela fermentação bacteriana (Mendonça et al., 2019). Tem capacidade de promover sustentação da derme, deixando- a firme e com mais elasticidade, colaborando para o 
rejuvenescimento, preenchimento de partes moles para corrigir rugas, sulcos, flacidez e assimetrias. A conduta biológica é bem comum, ao injetar o $\mathrm{AH}$, ele será absorvido progressivamente por meio do dióxido de carbono e água, por fim, será metabolizado pelo fígado (Pires \& Ribeiro, 2021).

O AH sintético foi criado em 1989 por Endre Balazs, porem a duração no organismo era de 24 horas. O injetável pode ter duas origens: animal, extraído da crista de galo; e sintética, por fermentação bacteriana através da cultura de Streptococcus, este tem sido utilizado com frequência nos últimos tempos (Nascente, et al., 2020).

Os preenchedores faciais atuais são divididos em absorvíveis e não absorvíveis, sendo que o primeiro permanece por apenas um período no local onde é injetado. O AH é o injetável mais utilizado para preenchimento facial dentre os absorvíveis, ele se destaca por ser metabolizado gradativamente em um período de 3 a 24 meses, dependendo da quantidade aplicada no organismo (Faria \& Junior, 2020).

O preenchimento dérmico ou subcutâneo tem como função suavizar indícios do envelhecimento promovendo rejuvenescimento facial. O procedimento deve ser seguro, eficiente, biocompatível, não alergênico e de fácil remoção. Diante disto o ácido hialurônico (AH) é o preenchedor mais utilizado para preenchimento de rugas estáticas, cicatrizes hipotróficas, aumento de volume labial, sulco nasogeniano, nasojulgal, correção nasal, volumização por perda de coxins gordurosos e remodelamento facial (Santoni, 2018).

Figura 2. Locais de aplicação do AH na harmonização facial.

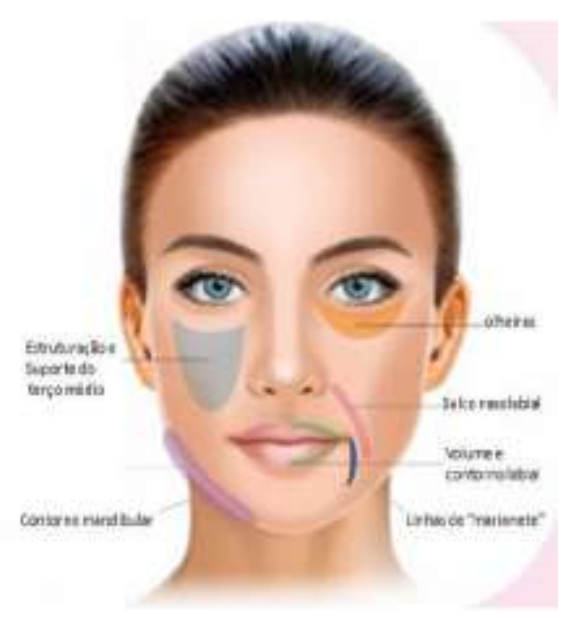

Fonte: Salvi e Maia (2018).

Segundo Ferreira e Capobianco (2016), a capacidade do AH em retardar o envelhecimento facial está relacionada as suas propriedades antioxidantes, aonde, o ácido hialurônico age nos radicais livres, aumentando a proteção da pele contra à radiação UV e contribuindo para o aumento da capacidade de regeneração tecidual. Além disso destacam que o AH proporciona volume, sustentação, hidratação, e elasticidade à pele, aprimorando a sua estrutura.

A utilização de preenchedores a base de $\mathrm{AH}$ aumentou consideravelmente se tratando de rejuvenescimento facial, que através da sua aplicação tem-se, vários benefícios para a qualidade dérmica. Com esse acréscimo, podem ocorrer efeitos indesejados, mesmo sendo uma matéria degradável pelo organismo, algumas situações requerem ações rápidas, por isso a importância da assistência pós procedimento (Castro \& Alcântara, 2020).

De acordo com Salvi e Maia (2018), o procedimento, habitualmente é realizado através de agulhas ou cânulas, das quais o calibre será apropriado a reticulação do preenchedor, área e profundidade de aplicação. A técnica poderá ser realizada por retro injeção, aplicações em bolus, injeções cruzadas, entre outras, levando em conta a viscoelasticidade do preenchedor 
escolhido. É necessário a união de vários métodos em um mesmo paciente, sendo uma abordagem individualizada para cada um desses e os resultados são correspondentes à habilidade do profissional.

Conforme Leite e Cardoso (2019), inicialmente os pacientes devem passar por uma anamnese para avaliação da indicação ou não do tratamento para que sejam investigados distúrbios de sangramento, gestação, hipersensibilidade, doenças autoimunes, diabetes descompensada, bem como também o uso de medicações ou fitoterápicos relacionados a anticoagulantes.

Segundo Dantas et al., (2019), o rejuvenescimento pode acontecer de duas formas, com prevenção ou tratamento, que podem se dar através de uma junção de condutas e procedimentos que visam minimizar o aparecimento dos sinais do tempo e formulações a base de ácido hialurônico que tem como objetivo retroceder as manifestações clinicas aparentes de uma pele envelhecida.

Quadro 1. Indicações do uso do ácido hialurônico em procedimentos estéticos.

\begin{tabular}{|l|} 
Região frontal \\
Sulcos nasolabial \\
Sulcos nasojugal \\
Aumento e volume do contorno labial \\
Labiomental \\
Linha da marionete \\
Região malar \\
Contorno e ângulo da mandíbula \\
Região do mento \\
Rino modelação \\
Têmporas
\end{tabular}

Fonte: Nascente, et al. (2020).

A aplicação do AH pode ser realizada em planos diferentes, com injeções no plano subcutâneo em regiões como nasolabial, linha de marionete, em áreas como malar, zigomático, mento, frontal e mandíbula é um plano mais profundo (supra periosteal), já o labial ocorre superficialmente. Pode ser usado agulha ou cânula, depende do nível de profundidade e reticulação do produto (Álvares \& Paiva, 2020).

O preenchimento utilizando a microcânula é menos invasivo, pois não são feitas punções como no método tradicional com agulha, porém, em ambos os modos poderá haver a necessidade de anestesia na área, dependendo da sensibilidade de cada paciente (Guidone et al., 2019).

O conhecimento da anatomia facial e fisiologia do tratamento é indispensável ao profissional que realiza o procedimento, para que minimize os riscos de injeção intravascular de $\mathrm{AH}$ e compressão do mesmo, evitando áreas com o propósito de prevenir complicações vasculares, formação de nódulos, necrose e morte (Fulco \& Silva, 2020).

Diante disso, o profissional tem que estar preparado e apto para controlar essas casualidades, dispondo da aplicação de uma enzima que degrade rapidamente e especificamente essa substância, utilizando a hialuronidase. Esse procedimento diminui a massa molar, modificando a sua viscoelasticidade, recuperando o fluxo sanguíneo local e evitando sequelas, sendo, portanto, apropriado para reduzir as reações adversas ocasionadas por excesso de preenchimento em locais inadequados (Atra \& Pereira, 2020). Não há na literatura uma dose recomendada de hialuronidase para reverter o preenchimento com ácido hialurônico, há sugestões que variam entre cinco e 75UI (Álvares \& Paiva, 2020). 


\section{Conclusão}

Evidenciou-se que o envelhecimento cutâneo é um processo incessante em que todos os indivíduos são acometidos e o AH ajuda na prevenção e tratamento, por possuir características antioxidantes, entrega volume, sustentação, hidratação, elasticidade sendo assim conveniente para correção de rugas e assimetrias reestabelecendo harmonia dos contornos faciais.

Dado que, na atualidade a busca pela qualidade de vida e melhora da autoestima, a utilização de técnicas minimamente invasiva da Harmonização facial como o preenchimento com ácido hialurônico tem sido mais atraente para reduzir os efeitos do envelhecimento.

$\mathrm{O}$ AH sendo é um preenchedor que contém um antidoto trazendo mais segurança e confiança para profissional e paciente.

Dessa forma, conclui-se que o uso do AH na harmonização facial fornece os benefícios necessários para uma pele saudável, com volume, sustentação, hidratação e elasticidade. Entretanto a escolha do produto e sua reticulação deve ser apropriada, atendendo as necessidades individuais de cada paciente proporcionando resultados satisfatórios.

Considerando as questões apresentadas nas publicações e as hipóteses levantadas, foi observado que o uso do ácido hialurônico oferece muitos benefícios no contexto dos procedimentos estéticos, entretanto, estudos futuros sobre as técnicas empregadas e as intercorrências nos procedimentos, devem ser analisados e publicados criteriosamente, para que a utilização da técnica se torne cada vez mais segura para o paciente.

\section{Referências}

Álvares, L. C. S., \& Paiva, L. M. (2020). Aplicação de hialuronidase para minimizar reações adversas associadas ao uso do ácido hialurônico na harmonização facial. Monografia (Graduação em Biomedicina) - Faculdade de Ciências da Educação e da Saúde, Centro Universitário de Brasília, Brasília.

Atra, M. A. T. E., \& Pereira, J. M. C. (2020). Harmonização Orofacial: Ácido Hialurônico e possíveis complicações. Monografia (graduação) - Universidade de Taubaté, Departamento de Odontologia.

Castro, M. B., \& Alcântara, G. A., (2020). Efeitos adversos no uso do ácido hialurônico injetável em preenchimentos faciais. Braz. J. Hea. Rev., 3(2), 29953005 .

Capobianco, M. P., \& Ferreira, N. R. (2016). Uso do ácido hialurônico na prevenção do envelhecimento facial. Revista Cientifica UNILAGO.

C.F.B.M., (2011). Conselho Federal De Biomedicina Resolução nº 197. Brasília.

Conceição, L. S., Lima, M. S., \& Santos, L. P. (2021). O uso do ácido hialurônico na Harmonização orofacial. JNT- Facit Business and Technology Journal. QUALIS B1. 1, 226-237.

Correia, G. V. O., \& Santos P. I. F. (2019). Preenchimento facial: tipos e características dos materiais disponíveis. Trabalho de conclusão de curso (graduação) Odontologia - Universidade Tiradentes.

Dantas, S. F. I. M., Lopes, F. P., Pinto, I. S. V. N., \& Lira, M. R. (2019). As eficácias a curto e longo prazo do preenchimento com ácido hialurônico no rejuvenescimento facial. Saúde \& Ciência Em Ação - Revista Acadêmica do Instituto de Ciências da Saúde.

Faria, T. R., \& Junior, J. B., 2020. Possíveis intercorrências do preenchimento facial com ácido hialurônico. Centro Universitário de Formiga - Unifor-MG, Formiga, MG - Brasil.

Fulco, T. O., \& Silva, H. L. O. (2020). Eficácia e segurança do preenchimento com ácido hialurônico para o tratamento de olheiras. ANAIS do VIII Simpósio de Pesq. e de Práticas Pedagógicas do UGB.

Guidoni, G. O., Oliveira, R. C. G., Oliveira, R. C. G., \& Freitas, K. M. S. (2019). Anatomia do lábio e preenchimento labial com micro cânula para melhoria estética: relato de caso. Rev. UNINGÁ, 56(S3), 24-32.

Haddad, A., Kanduc, B. V., Guarnieri, C., Noviello, J. S., Cunha, M. G., \& Parada, M. B. (2017). Conceitos atuais no uso do ácido poli-1-láctico para rejuvenescimento facial: revisão e aspectos práticos. Surgical \& Cosmetic Dermatology 9(1):60-71.

Leite, R. G. V., \& Cardoso, T. M. M. (2019). Preenchimento labial com o uso do ácido hialurônico. Revista Científica Semana Acadêmica.

Maia, I. E. F., \& Salvi, J. O. (2018). O uso do ácido hialurônico na harmonização facial: uma breve revisão. Brazilian Journal of Surgery and Clinical Research - BJSCR. 23(2), 135-139.

Mendonça. A. J. P. C., Duarte, I. K. F., Neto, J. F. T., Silva, J. L. V., \& Neto, J. M. A. S. (2019). O uso do ácido hialurônico na harmonização facial: Uma revisão de literatura. Revista Eletrônica Acervo Saúde / Electronic Journal Collection Health, 32. 
Research, Society and Development, v. 10, n. 14, e94101421731, 2021

(CC BY 4.0) | ISSN 2525-3409 | DOI: http://dx.doi.org/10.33448/rsd-v10i14.21731

Munhoz, G. N., Santos, T. L. T., Souza, K. D., \& Segna, L. E. O. (2020). O uso do ácido hialurônico para retardar o envelhecimento cutâneo. CONIC / SEMESP $20^{\circ}$ Congresso Nacional de Iniciação Cientifica.

Nascente, F. M., Sobrinho, H. M. R., Souza, C. M. D., \& Vasconcelos, S. C. B. (2020). O uso do ácido hialurônico no rejuvenescimento facial. Revista Brasileira Militar de Ciências, 6(14).

Oliveira, B. S., Uribe, N. C., \& Coimbra., D. D. (2014). “Quadralização facial” no processo do Envelhecimento. Surgical \& Cosmetic Dermatology, 6(1), 65-71 Sociedade Brasileira de Dermatologia.

Pires, Y. S., \& Ribeiro, P. M. C. (2021). Harmonização orofacial e o uso do ácido hialurônico e toxina botulínica: o poder de restituir autoestima. Id on Line Rev. Mult. Psic. 15(56), 252-260.

Santoni, M. T. S. (2018). Uso de Ácido Hialurônico Injetável na Estética Facial: Uma Revisão da Literatura. Especialização em Estética e Saúde - Universidade Regional do Noroeste do Estado do Rio Grande do Sul - UNIJUÍ.

Sundaram, M. D. H., \& Fagien, M. D. D. E. (2015). Dermatologia, Cosméticos e Laser Surgery; e prática cirúrgica privada. Private Practice. 